\title{
Dos argentinas ante la Guerra Civil española. Novela transatlántica para una memoria descentrada en Mika, de Elsa Osorio ${ }^{1}$
}

En este trabajo analizo la novela Mika (2012), atendiendo en particular a la configuración del personaje de Micaela Feldman de Etchebéhère, argentina que combatió en la Guerra Civil española. El marco de ficción está dado por la convergencia entre la apelación a documentos y fuentes orales rastreables, con una apuesta por las operaciones de selección y combinación de los materiales propias de la función poética del lenguaje. El marco teórico específico aquí corresponde a los estudios de la memoria que atienden a la retroalimentación y a la fusión entre lo materialmente documentado y las vías de ficcionalización a través de conceptos como "memoria novelada" o "docuficción". Considero especialmente el interés de Osorio por una materia histórica en principio foránea, y la elección de una impronta narrativa que abreva en géneros en apariencia reñidos con una potenciación del relato histórico. Esta memoria puede calificarse como "descentrada", pues a pesar de que la propia Micaela Feldman de Etchebéhère ya había escrito sus memorias, se elige una escritura que desplaza el texto original respecto del núcleo dado por la autoría fija, se lo apropia y lo pone en diálogo con una nueva mirada y con diferentes mecanismos desestabilizadores.

La novela Mika, de la autora argentina Elsa Osorio, publicada en 2012 en Argentina bajo el sello Seix Barral, supone un acercamiento literario muy particular a la figura de una mujer que vivió momentos cruciales de la Guerra Civil española, que combatió desde un lugar de mando en el frente de batalla, a la cabeza de decisiones y de una exposición riesgosa y sostenida. Micaela Feldman fue, según se ha sabido hasta el momento, la única mujer argentina que llegó a esas condiciones de protagonismo bélico en los primeros tiempos del conflicto extendido entre 1936 y 1939 en España, conflicto tras el cual sobrevino una dictadura de treinta y seis años, la franquista.

Es probable que los pocos datos biográficos apuntados en el párrafo anterior den cuenta de la riqueza que alberga la historia de Micaela Feldman y el provecho narrativo que puede potenciar un abordaje escrito de sus vivencias. Asimismo, el antes y el después de la lucha en España 
ofrecen un amplio espectro de particularidades. La manera en que Elsa Osorio literaturiza la vida, y especialmente la participación en la guerra de España de esta mujer excepcional, conlleva una serie de decisiones formales y una apelación a determinados procedimientos que multiplican las capas de una aproximación en principio plausible de ser identificada meramente como "biográfica". No es solo un detenimiento en un período vital lo que se lleva a cabo, ni tampoco una porción del concepto de bíos aquello que se aborda de modo literario, sino muy especialmente un aprovechamiento del otro componente del origen griego de la palabra "biografía", es decir, que se destaca el énfasis en la grafé, en las operaciones de escritura. Esto hace que la memoria puesta en marcha sea una memoria novelada:

[L]a literatura se hace presente como una vía eficaz ante la dificultad de transmitir una experiencia traumática y evitar que se convierta en simple estadística. Es igualmente una entrada imprescindible para revelar los modos que el pasado encuentra para permanecer en la memoria colectiva y cómo los sucesos conflictivos no resueltos están impregnados de sentidos que la historia no es capaz de indagar o que llanamente desestima. (Macciuci 18)

Como adelanto de esas operaciones literarias, cabe al menos mencionar aquí que los diferentes capítulos que abordan la vida de Mika están compuestos por el empleo de la primera persona singular, instalando la presencia de una voz narradora. Incluyen también otra primera persona singular que ficcionaliza la voz del personaje narrado. A su vez, encontramos la interpolación de alusiones en segunda persona singular. Por medio de estas últimas se apela a la protagonista de manera coloquial, con un mecanismo tendiente a una marcación de cercanía que presenta otra tipografía. La letra cursiva coloca en otro plano esa referencia directa, ese cara a cara narrativo cuasi conversacional y ficticio a través del cual, como en un intento de confesión, se va desgranando lo más doloroso, lo más sentido de la guerra. Viene a cuento anunciar también que dicho empleo de la segunda persona implica por momentos cierto grado de omnisciencia, característica que suele corresponder a la narración en tercera persona, por lo cual prevalece un efecto de superposición entre zonas de conocimiento certero y pasajes más subjetivos e interpretativos, que tienden a crear una empatía en la experimentación de momentos dramáticos extremos en el pasado.

ALCANCES LITERARIOS DE LAS IDENTIDADES MÚLTIPLES

La complejidad del personaje elegido para la poetización de una lucha in- 
tensa y peligrosa se manifiesta también en un plano en apariencia solo denotativo, como lo es el terreno del nombre propio. Micaela Feldman, nacida en un pueblo de la provincia argentina de Santa Fe, Moisés Ville ubicado a poco más de trescientos kilómetros de Rosario, ciudad a la que se trasladó luego, antes de su arribo a Buenos Aires - pasa a ser Mika, tanto para sus allegados y amigos como para los integrantes de la columna del POUM (Partido Obrero de Unificación Marxista) que llegó a capitanear durante la Guerra Civil. En el sobrenombre afectuoso sin duda resuena un pasado cercano, el de su familia, de origen judío, que llegó a Argentina huyendo de la persecución durante la época zarista en Rusia. Pero a su vez, la unión con un militante comunista argentino de origen francés, Hipólito Etchebéhère, la conduce a otra denominación en la documentación del matrimonio que concretan muchos años después del inicio de su convivencia. En términos formales, Mika pasa a ser en determinado momento Michèle Etchebéhère. Ese cambio se produce para realizar visitas autorizadas en el marco de la internación en la que Hipólito (Hippolyte en Francia, Hippo en la intimidad) se recupera de una enfermedad que lo aqueja desde el comienzo de su lucha política, desde el abandono de la casa paterna, debido a una sensibilidad político-social que nace en él a la luz de los acontecimientos de la Semana Trágica. ${ }^{2}$

Con Hipólito, Mika (que para su marido será Mikusha, actualizando una vez más la resonancia rusa) compartió la lucha a favor de los obreros en Argentina, participó en la política estudiantil universitaria (Mika se graduó como odontóloga, profesión que ejerció), se instaló durante algunos años en la Patagonia para escapar del fantasma de la tuberculosis que aquejó a su compañero - en un viaje en el que proyectaron juntos la escritura de la represión obrera que finalmente concretaría años más tarde Osvaldo Bayer en La Patagonia rebelde -, y con él también viajó a Europa para luchar contra el fascismo.

Por otra parte, y ya en un terreno de ocultamiento nominal en pos de una escritura más libre, nos encontramos con la funcionalidad del seudónimo, y con la fugaz intriga y la complicidad que entraña su desvelamiento:

Una sonrisa pícara y baja el tono de su voz: en verdad era Analía Cárdenas la autora de esos artículos [sobre la vida cultural en París] que se publicaron durante años en un periódico de Río de Janeiro ... [A] unque a veces tenía conflictos con Analía, ella era mucho más abierta que yo, lo que era imprescindible para la columna, y me rompía los papeles cuando yo me ponía muy dura con un autor por alguna actitud que yo juzgaba reaccionaria o frívola. (Osorio, Mika 128) 
Esta clase de ocultamientos también recuerda, ya con un sesgo más peligroso, con riesgo de persecución, las máscaras necesarias para publicaciones de mayor compromiso político, algo que también atañe a su compañero y al proyecto que los reunió inicialmente: la revista universitaria Insurrexit, publicada entre 1920 y 1921 (Tarcus) y el grupo homónimo del que ambos formaron parte, un colectivo de militancia estudiantil atento a la lucha obrera y a la posible integración en el partido comunista al que ambos se afiliaron y del que fueron expulsados.

Si hay en la novela de Elsa Osorio un condimento que potencia especialmente la intriga, que ya de por sí despiertan los acontecimientos históricos asociados a la vida de Mika, es el que ofrece la triple identidad de un personaje muy peligroso, un enemigo interno, espía soviético que en diferentes momentos cruciales (y bajo diferentes nombres) pone en riesgo a la protagonista. Más allá de la posibilidad - y de la pertinencia y necesidad, como se tratará en el apartado siguiente - de cotejo explícito entre la ocurrencia real detallada de los acontecimientos más puntuales, cabe una alusión analítica a esa sobreimpresión de identidades, porque condensa la mirada literaria macro que atañe a las internas del antifranquismo, especialmente a la persecución del trotskismo por parte del estalinismo; pero incumbe también a la mirada literaria más íntima, aquella que se detiene en los padecimientos y las amenazas que alcanzan a Mika en tanto mujer en situaciones muy hostiles. En tal sentido, Raquel Macciuci observa un cambio de foco en este tipo de decisiones estéticas:

Otra tendencia que busca entender el pasado sin atarse a matrices existentes queda expresada en el interés por la vida privada o los aspectos menos conocidos de los grandes personajes públicos a partir de materiales que también han sido rejerarquizados por la memoria y la cultura de la posmodernidad, como ocurre con los géneros del yo: la autobiografía, los relatos orales, la crónica, el periodismo de investigación. (41)

En la novela, el joven y atractivo Jan Well, a quien Mika e Hippo conocen en Alemania en pleno ascenso del nazismo, a comienzos de los años 30, se presenta desde el inicio como un personaje tan interesante como amenazador. Convergen en él una mirada impertinente hacia Mika, mirada cargada de deseo que mina el ambiente de camaradería que los une en la lucha contra el fascismo, y una capacidad para sembrar discordia entre compañeros, malversando el contenido de las diversas opiniones emitidas. Allí se cuela el lugar común algo sexista de atribuir a la intuición femenina un mayor dominio de esas presuntas pequeñeces - que terminan siendo no tan presuntas ni tan pequeñas - ya que Mika se muestra desconfiada y 
desafiante con Well, quien intentará abusar de ella sexualmente en una ocasión en la que Hippo es detenido por un breve lapso de tiempo. Tras ese episodio, en el que ella logra defenderse, Jan Well se eclipsa y reaparece pocos años después en España, ya en plena guerra. Allí pasa a ser Andrei Kozlov, quien en principio procura, desde las sombras, conocer la situación de Mika hasta que logra que la detengan, valiéndose de una amante que le brinda información. Esta mujer es a su vez la amante de un militar republicano de alto rango, lo cual agrega una dimensión casi folletinesca a la narración de la guerra en la primera línea de fuego y en las trincheras.

Como en una suerte de novela por entregas, se le va dosificando al lector de manera episódica una tensión que va en aumento. El reencuentro presencial entre Andrei Kozlov, el nuevo seudónimo que en realidad oculta la identidad del espía Ruvin Andrelevicius, se da en una oscura celda en la que este intenta por segunda vez abusar de Mika. El ataque también en esta ocasión resulta infructuoso. Los nombres falsos de Jan Well y Andrei Kozlov enmascaran entonces a Ruvin Andrelevicius, joven lituano que había ido a Moscú lleno de esperanzas, pero que se deshumanizó y pasó a ser un número, el soldado 32, en un fanatismo acrítico encarnado en su rol de agente de la policía política soviética. Desde ese mismo fanatismo, cree que puede convencer y adoctrinar a la mujer que lo atrae:

Curioso, lo que Jan quiere Mika lo podría enunciar del mismo modo: una sociedad igualitaria. Carcelero y presa tienen el mismo sueño y comparten su fe marxista en el futuro, pero mientras ella está convencida de que esa máquina de destruir que es el estalinismo está ahogando la revolución, para él es esencial la más absoluta sumisión al Partido Comunista, a los intereses de la Unión Soviética. - Si hay que ser duro ahora, Mika, es para que la revolución triunfe. $(254)^{3}$

Sin embargo, la violencia física reduplica la obnubilación ideológica, y el sustrato común que atraviesa el posicionamiento político de ambos se diluye en una nueva defensa. En Alemania había logrado evadirse Mika de su agresor por medio de una patada en los testículos. En el encierro en una cárcel española por parte de su propio bando, se evade a través de la afrenta humillante de un escupitajo en la cara de su agresor.

El soldado 32 no ha pasado a la historia. La errancia de esos volátiles nombres que impiden cualquier atisbo de identificación certera podría haber tomado cuerpo en otro soldado, en otro número. Esta intriga extra, con todos los componentes que intensifican un sesgo de thriller con sexo, violencia y política, está presentada como algo que excede los documentos rastreables de Micaela Feldman a los que se alude desde la instancia narradora (pero quien se menciona como el que resuelve la liberación de 
Mika es nada menos que el destacado anarcosindicalista Cipriano Mera, militante de la Confederación Nacional del Trabajo). Queda entonces sembrada la inevitable existencia de un resto de la historia, un desplazamiento de los núcleos temáticos ya narrados por la protagonista, algún vestigio de ficcionalización cuyo disparador en el plano referencial no es necesariamente aprehensible mediante algún tipo de certificación. Sobre la base de toda la complejidad registrada hasta el momento, es preciso ir perfilando la idea de que el trabajo de memoria de la narración biográfica de Mika está plagado de desvíos, saltos, interrupciones, descentramientos respecto de lo que podría ser un único eje argumental en torno a la heroína.

Además de la materia onomástica, bajo la que subyacen aspectos significativos para la trama, es menester dar cuenta de que esta historia fue publicada por Elsa Osorio con otro título en España: La capitana. Esa opción paratextual imprime una mayor distancia en el tratamiento del personaje. El rango militar en lugar del apelativo en la portada del libro otorga una impronta de menor familiaridad. No obstante, cabe apuntar que las cuestiones jerárquicas en el bando republicano - defensor del régimen legalmente instituido de la Segunda República que resistió la sublevación militar del 18 de julio de 1936 - fueron en ocasiones fruto de la necesidad del día a día de las batallas. Por este motivo, el título de "capitana" acarrea la rareza de un ascenso nada habitual entre mujeres, como así también un guiño con el que se le da unicidad y un sitio en la Historia, que desmarca al sujeto de la individualidad del nombre para instalarlo en el devenir de los acontecimientos. ${ }^{4}$

\section{LA DOCUFICCIÓN COMO MARCO TEÓRICO}

Una característica muy propia de la narrativa de la memoria pasa por la fusión, la convergencia, la superposición o la adyacencia de documentos materiales (reproducidos, reseñados o aludidos) y contenidos ficcionalizados. El género biográfico, y particularmente el terreno de la biografía novelada, son campos fértiles para dichos cruces. Esto ha llevado a que se acuñara el neologismo docuficción, que sintetiza los diferentes modos capaces de adoptar las relaciones antes aludidas:

Aparte de la revitalización de géneros tradicionales como la novela histórica, el filme histórico, el teatro documental y la película documental se observa, desde mediados de la década de los noventa, una extraordinaria coyuntura de formas híbridas en las culturas europeas, estadounidenses y latinoamericanas en las que se entrecruzan elementos y estrategias representativas ficcionales y no ficcionales. (Tschilschke y Schmelzer 11) 
Siguiendo a Christian von Tschilschke y a Dagmar Schmelzer, con el término "docuficción" se alude a un modo representativo que trasciende barreras mediáticas y de género en el que se entrecruzan elementos, técnicas y estrategias documentales y ficcionales. En esta definición, el "documento" es un texto que se vincula a un propósito de facticidad, o sea, que su verdad o su falsedad puede ser puesta a prueba, mientras que lo "ficcional" es aquello que no admite ser sometido a dicha prueba (16). La permeabilidad de los compartimentos de la documentación y la ficción es ya irrefutable. Antonio Gómez López-Quiñones sostiene que la característica que se destaca es la "preocupación por mostrar el origen de la información, por explicarle al lector cómo, quién, dónde y para qué se logra un determinado dato posteriormente incluido en la trama" (16). Esa preocupación es la que desgrana la voz narradora predominante en Mika, que podemos hermanar con la instancia de autoría de Elsa Osorio; pero que en absoluto cabe homologar sin matices, pese a que todos los señalamientos extratextuales de búsqueda parecen declarar el método seguido para componer la novela:

Escribiste esas notas infinitas veces, a lo largo de casi cuarenta años. Algunas las tengo, otras las vi en París, y las describí para no olvidarlas nunca. Las extiendo sobre mi mesa de trabajo. Manuscritas en diversos colores de tinta, a máquina, en una hojita suelta pequeña y gruesa y en una grande que es copia en carbónico de vaya a saber qué original, en las hojas vacías de una agenda alemana de 1935, en un cuaderno de tapa negra, en una libreta de hule anaranjada, en un artículo en la revista Sur de 1946 que firmás con tu nombre, donde hablás de la guerra, y en los márgenes de otro, que escribís bajo seudónimo para un periódico brasilero, que nada tiene que ver con la guerra de España.

Notas sobre notas sobre notas, te has pasado la vida borroneando esos recuerdos, hasta que al fin, en 1975, publicaste tus memorias sobre la guerra en Francia. (168; cursiva en el original)

Como se anticipaba, las cursivas son empleadas de manera recurrente a lo largo de toda la novela para dirigirse a la protagonista en segunda persona. Son la materialización de un diálogo imposible. La novela fue escrita entre dos ciudades, París y Buenos Aires, y entre dos fechas distantes explicitadas al final, marzo de 2007 y mayo de 2011. Mika había muerto en 1992 y, pese a que Elsa Osorio ya había accedido a algunas fuentes que motivaron, con cierta discontinuidad, el acercamiento a la figura de Mika y el interés por la literaturización de su vida, no se produjo ningún encuentro presencial ni ninguna conversación, aunque fuera a distancia, entre ambas. El núcleo de este relato de memoria, por tanto, nunca es 
alcanzado de forma completa. La recapitulación narrativa no se afirma en un único terreno firme, susceptible de algún grado de centralización en el dominio de la historia que se pretende contar. Ese ejercicio de una memoria desplazada etaria y geográficamente habilita fértiles licencias literarias.

El espacio de las intervenciones en segunda persona antes mencionado, en un tono entre cómplice e íntimo, por momentos peca de cierta distancia superadora, quizá por eso se resiente un poco la verosimilitud que construye la novela. Es una omnisciencia mixta, pues por un lado la voz narradora entra y sale de los pensamientos del personaje, y arroja a los lectores el producto de esa indagación, pero a su vez parece estar explicándole al propio personaje lo que vivió y sintió. De todos modos, este análisis de la configuración de ese terreno limítrofe, dado en la novela en los párrafos tan particulares de cursiva y uso de la segunda persona, no apunta a señalar un disvalor literario. Resulta fructífero para tener en cuenta otra dimensión en principio divergente de la escritura literaria y de todo asomo de ficcionalización: la publicación en prensa de un artículo firmado por Elsa Osorio respecto de Mika, un germen de escritura periodística que va dando muestras de la necesidad de emplear otro lenguaje para contar su historia, un lenguaje estético. Estas puntualizaciones son realizadas por Osorio en un apartado final - una vez concluida la novela - que se titula "Postfacio y agradecimientos".

Llama la atención que en el periódico ya despunte un procedimiento más propio del género en el que finalmente se plasma la vida de Mika, y también la forma en que se va gestando una empatía que delinea y justifica el rol de la escritora, desde el que se construye un lugar de identificación con el personaje:

Pocos días después de que él [Juan José Hernández, quien le habló por primera vez de Mika] me descubriera a Mika, en 1986, devoré Ma guerre d'Espagne à moi, sus memorias de la Guerra Civil, que publicó De Noel en Francia en 1975. ¿Cómo era posible que yo, que soy argentina como Mika, nunca hubiera escuchado hablar de una historia tan extraordinaria?

Para corregir el injusto olvido, publiqué un artículo en la revista Crisis en 1988. ¿Sos trotskista?, insistieron. Esa manera de reducir la historia a encasillamientos habría de ser un escollo con el que iba a chocar más de una vez ... piedras en el camino ... que se han ido acumulando unas sobre otras hasta construir un muro mohoso, que impidió que figuras como la de Mika - y tantos otros antifascistas que vivieron la gran aventura intelectual y revolucionaria del siglo XX - tomaran su verdadera dimensión. No hay partido o agrupación política que deje la epopeya de 
Mika como legado a las generaciones venideras. Mika Etchebéhère es una de las grandes olvidadas de la Historia.

¿Anarquista, comunista, trotskista, opositora de izquierda al estalinismo, del grupo Que Faire, del POUM? Todas estas clasificaciones, y ninguna de manera definitiva, podrían caberle a Mika ... En 1990 publiqué otro artículo sobre Mika en Todo es historia, la revista que dirigía Félix Luna. No recuerdo por qué elegí la segunda persona - tan poco adecuada al periodismo -: yo le contaba a Mika lo que había leído en su libro. Lo titulé "Carta abierta a Mika Etchebéhère". Era sólo una manera de acercar su historia al lector. Uno inventa una combinación de palabras, y ellas acaban por inventarlo a uno: la segunda persona me dio una proximidad que no tenía. Y una osadía. Mika vivía entonces, pero nunca se me había ocurrido la idea de hablarle... (293-294)

La extensión de la cita anterior se justifica porque encierra varios aspectos que hacen a la decisión estética de un procedimiento de ficcionalización, el de la referencia en segunda persona, que migrará del artículo a la novela. Pero también se da en estos párrafos toda una declaración de la funcionalidad ("misión" llega a sugerirse incluso) de realizar una suerte de rescate del olvido. La autora desnuda ese atrevimiento en los agradecimientos - instancia que es también un blanqueo y un reconocimiento en todo lo que tiene que ver con la cesión de fuentes documentales - de manera que va acercando la posición de autoría y las vivencias de la mujer biografiada. El tinte mesiánico de este desvelamiento de una historia silenciada forma parte de un juego que reúne los datos, las cartas, las anécdotas transmitidas verbalmente, con un halo de imaginación como pieza irremplazable, donde conviven ideas de misión y de vaticinio:

Vos vas a escribir sobre Mika, vaticinó Juan José Hernández en 1986, aunque yo estaba lejos de concebir un libro. Y lo repitió, con certero entusiasmo, en 1996, en mi ático de Madrid, cuando yo le conté las curiosas peripecias de la investigación. Y en diciembre del 2006, en su departamento en Buenos Aires, después de escuchar mis últimos hallazgos, con vehemencia: Dejate de buscar y buscar, Elsita, ya está, ahora escribila.

Tenías razón, Juanjo querido, era hora de salir de aquella trampa. Aunque sé que no hay posibilidad de memoria sin imaginación, un excesivo respeto a mis personajes, comprometidos hasta el tuétano con su época, me tenía presa de pies y manos a una historia que crecía, como un cuerpo extraño, en todas direcciones. Aquellos documentos inéditos, aquellos sorprendentes manuscritos que había encontrado, ejercían sobre mí un especial embrujo, un cierto delirio de misión, me pedían otras búsquedas, más datos... (292) 
Es digno de destacar cómo se otorga voz a alguien que autorice, que dé el aval para garantizar que se está avanzando en el sentido correcto, o en el que se desea ir. La autorización llega con el coloquialismo del "Elsita" por parte de alguien que ha presentado el personaje a la autora, brindándole la materia prima para la creación literaria. Un desenlace lamentable, pero que también funciona poéticamente, es incluido en este apartado: Osorio llega a enviar un boceto, un embrión de lo que será la novela, a Hernández; pero, en una coincidencia que acentúa demasiado una seguidilla de casualidades, este muere la misma tarde en que la autora se encuentra caminando conmovida por el jardín de Mika y en ese mismo mes de marzo de 2007 en que se empieza a escribir la novela.

En este punto es menester insistir en que otra zona de encuentro entre imaginación e historia se produce en el postfacio y que se subraya, aunque de manera algo marginal, entre paréntesis, lo siguiente: "(Recuerdo al lector que esta nota no es ficción)" (295). Es interesante la necesidad de aclarar, ya que, contagiada por el afán de literaturización, aun este espacio más descriptivo de procedimientos y fuentes puede despertar alguna desconfianza, como si la ficcionalización contase con un plus en el acomodamiento de los materiales de los que se dispone, y como si a la exacerbación insistente de coincidencias por fuera de la ficción le conviniera una operatoria poética de selección. ${ }^{6}$

No nos detendremos aquí en un evidente malestar entre la gestación de esta novela y el acceso formal a los documentos vinculados a Micaela Feldman. Elsa Osorio expone los nombres de aquellos sujetos que conocieron a la persona de carne y hueso, y detalla, asimismo, qué le brindó cada una de esas fuentes. Sin embargo, se señala un límite frente a todo aquello de lo que se podría disponer. Se explicita que Arnold Etchebéhère, sobrino político de Mika, le mostró una serie de documentos (partida de defunción, certificado que daba fe de la muerte de Hipólito) que permiten acceder a certezas de registro civil. Pero más allá de las puertas que se van abriendo, es necesario mencionar que hay una denuncia oblicua (ya que no se explicitan destinatarios concretos) respecto de un presunto mal manejo de los fondos documentales. El acceso a los papeles de una manera más acabada se da gracias al poeta y militante trotskista Guy Prévan, amigo de Mika desde los años sesenta:

Al principio, sólo me mostró recortes de prensa sobre el libro de memorias de la guerra de Mika ... Me llevó varios viajes a París y muchas horas de fascinantes conversaciones con Prévan poder llegar a todos los archivos. Los fui paladeando poco a poco, en la medida en que ganaba su confianza. Las cartas entre Mika e Hipólito, notas de lecturas de los dos que me llevaron de libro en libro, cartas de 
amigos, los cuadernos de París, de Berlín, la agenda alemana, las libretas. Dos cartas de Alfonsina Storni que Prévan me regaló, una carta y una tarjeta de Cortázar. Yo tomé notas, saqué fotocopias. Un día decidió prestarme los cuadernos y las cartas para que yo pudiera trabajar con ellos todo el tiempo necesario en mi casa en Madrid. Gracias a su generoso gesto pude escribir esta novela. Leí a mis anchas, descifré letras, archivé, y en mi siguiente viaje, le devolví los documentos. Siempre iba a poder consultarlos en su casa. Pero cuando varios años más tarde quise verificar un dato, Guy Prévan ya no los tenía. (296)

La imposibilidad de acceder a las fuentes documentales señala hacia Argentina. Probablemente entrañe una complejidad de puntos de vista encontrados acerca de la posesión, la clasificación, los derechos y el acceso público, que en este trabajo nos excede, pero cuyo estudio resulta interesante a los efectos de advertir cómo la posibilidad de una memoria novelada pudo trascender esos accesos denegados: ${ }^{7}$

Después de tanta búsqueda, de tanto viaje, hoy los escritos de Mika e Hipólito Etchebéhère están mucho más cerca, en la misma ciudad en la que vivo, Buenos Aires, en una biblioteca especializada. Pero ni yo ni nadie los puede ver, están "catalogándose" hace años, los niegan sistemáticamente y hasta han desaparecido del sitio web de la institución, donde hasta hace un tiempo se exhibían como uno de sus tesoros. (297)

Por lo general, la apelación a materiales documentales tiene la función de tornar verosímil aquello que puede ser puesto en duda. Sin embargo, la convivencia antes aludida entre documentos escritos o fuentes de distinto tipo y las decisiones estéticas del lenguaje artístico propio de una novela, además de tender líneas que parecen otorgar autoridad a un procedimiento serio, documentado, también contribuye a la difuminación de límites de los compartimentos involucrados en esa misma convivencia. El pacto de lectura que se instala incluye la posibilidad de que se vaya vaciando de sentido una demarcación estricta entre uno y otro dominio, el del documento y el del texto de creación literaria.

Así como en su momento veíamos que se dificulta la certeza sobre la identidad del "soldado 32" (con la advertencia de que es un episodio que se silencia en las memorias de Mika), la búsqueda de un cotejo término a término entre lo que se ha materializado en las fuentes documentales y lo que se narra en la novela no tiene más que un efecto probatorio que no afecta al texto literario. Con esto de ningún modo se quiere decir que no importa que lo narrado haya ocurrido o no, pero desde la hibridación aludida y en el análisis que se está desarrollando aquí, la diferenciación 
entre lo intratextual y lo extratextual no afecta a la constitución de una verdad que el texto crea sin falsear los hechos.

LOS TIEMPOS DE LA MEMORIA. UNA “ANTI-CRONOLOGÍA” DEL PASADO TRAUMÁTICO

La novela de la memoria suele presentar un orden cronológico relativamente estable, en el que no se excluyen incisos anafóricos y catafóricos que desestabilizan un avance rectilíneo en un tiempo progresivo. Esos incisos desestructuran una progresión que da cuenta de un avance temporal, y son por lo general empleados para demostrar una marcha trabajosa en la indagación del pasado traumático. En la novela de Osorio se propone otro orden, que despliega un mosaico de tiempos y espacios en los que un año clave, 1936, y lugares vinculados a la Guerra Civil funcionan como pivotes de otras fechas y latitudes.

La novela está estructurada en tres partes. Los títulos de los capítulos presentan siempre esa estructura: el lugar y la fecha. En la primera parte, Sigüenza (septiembre de 1936), Buenos Aires (1919 a 1923) y Moncloa (noviembre de 1936) adquieren el mayor protagonismo, con algunas incrustaciones de París en 1992 y de Moisés Ville en 1902 (muerte y nacimiento de Mika respectivamente), y de la Patagonia. No detallaremos las otras dos partes de la novela, pero basta este panorama de sitios y años para señalar un manejo del tiempo cuyo sentido se podría debatir desde diferentes hipótesis. Lo que sobresale es un reordenamiento deliberado, que va a la par con el camino tentativo, no metódico en términos estrictos, del discurso de la memoria.

Una cierta circularidad alcanza a toda la novela, ya que también el último capítulo de la tercera parte corresponde a 1936. Pero si bien los saltos temporales internos son innegables, es muy significativo que esa última referencia de 1936 corresponda a agosto, y particularmente a Atienza, batalla en la que llegó a participar Hipólito. Luego de ese enfrentamiento, Mika asume el mando de la columna del POUM que él tenía a su cargo. Aquello que se resiste a ser contado - que se posterga, en una decisión estructural altamente poética que espeja el orden por momentos caótico y tentativo de la memoria y del acceso a los documentos -, es la muerte del ser más querido, que paradójicamente es también el inicio del compromiso más genuino con la guerra de España por parte de Mika. En este sentido también es coherente que el París de 1992, escenario de la muerte de Mika, anteceda al capítulo de Moisés Ville 1902, su nacimiento. Se va estableciendo una cronología fragmentada que termina vaciando de sentido la necesidad de anclaje a unas coordenadas de espacio y tiempo predecibles. Sin que se llegue a la a-historicidad de la novela de 
fragmento, ocurre que "cada capítulo no posee necesariamente conexión evidente con el siguiente. Puede surgir otra problemática, otros personajes, en menor grado otros cronotopos o espacio-tiempos" (Cifuentes Aldunate 234).

En elecciones estructurales y de punto de vista, la voz narradora ficcionaliza el acompañamiento de su personaje, que la autora declara en el postfacio, también con un tono bastante literario:

No imaginaba que esa historia habría de acompañarme como un río paralelo a mi vida, que se sumerge y vuelve a salir a la superficie. Me zambullí en su vida y desistí de contarla varias veces, hasta que por fin nos abrazamos en esta novela.

Y recalco "novela", aunque se apoya en documentos históricos. La elección de las situaciones y los personajes responden a las necesidades de la narrativa.

Los capítulos de la guerra siguen, batalla a batalla, lo más fielmente posible, las memorias de Mika y otros libros que consulté. Elijo contar la guerra desde la óptica del POUM porque es la de mis personajes. (Aunque, a esta altura, no exagero si digo que soy del POUM, pero no partí de allí, son mis personajes quienes me llevaron). (291)

Nótese cómo la declaración de empatías constituye una mostración procedimental y define el ejercicio de descentramiento memorístico llevado a cabo. Por un lado, se reconoce que la voz narradora ha abandonado su rol primigenio para, por momentos, superponerse con el personaje. Por otra parte, se admite que los documentos de ninguna manera implican el núcleo de la escritura, sino su literaturización. Por último, es interesante que se explicite desde qué óptica se narra, la de un partido tan distante como ajeno. Esta presunta dispersión respecto de los lugares de enunciación más cómodos y previsibles facilita la fusión de lo verificable y lo inventado.

MEMORIA DESDE LA OTRA ORILLA: TODAS LAS GUERRAS, LA GUERRA Más allá del sustrato teórico dado por la docuficción, la memoria de la Guerra Civil española que se lleva a cabo en el abordaje literario que aquí se está trabajando puede ser puesta a la luz de diferentes marcos de reflexión teórica. Estos contribuirían a dar cuenta de una narración de algún modo alternativa, descentrada también en la elección de sujetos y episodios largamente soslayados que se aspira a rememorar.

La memoria es la que ... posibilita rescatar del pasado, partes de la historia que han quedado silenciadas, arrinconadas por la historia dominante de los vencedores. De ahí, la importancia de los testimonios y que traten en primer lugar de hacer hablar 
a las víctimas, a los testigos de las víctimas o a los que los recuerdan. (Corredera González 13)

La atracción por unos acontecimientos obstruidos durante décadas debido a la imposición de silencio determinada por los vencedores de la Guerra Civil resurgió en la propia España alrededor del último entresiglos, y lo hizo en consonancia con un resurgimiento que abarcó también el plano histórico (sobre todo a partir del nacimiento de la Asociación para la Recuperación de la Memoria Histórica y la apertura de algunas fosas comunes a las que se habían arrojado los cuerpos de republicanos asesinados) y el plano jurídico (sobre todo en el impulso, luego abortado, que cobró el tema a partir del trabajo de revisión a cargo del destituido juez Baltasar Garzón).

Ahora bien, a pesar de que este renacimiento y la fuerza con la que se dio en la narrativa de los últimos quince años fue un verdadero fenómeno, asistimos en el caso del texto de Osorio al acercamiento por parte de una autora argentina que ya había abordado literariamente una temática de memoria del pasado dictatorial argentino con un libro paradigmático en relación con el tema del robo de niños, $A$ veinte años, Luz, publicado por primera vez en $1998 .^{8}$ Es cierto que la autora, a pesar de que vive en Argentina, tiene una relación muy estrecha con España, ha vivido allí y se halla con frecuencia en Europa, por lo cual el interés por el pasado bélico, que aún da muestra de consecuencias en la sociedad española, en su caso de ningún modo es un interés advenedizo o casual.

Sí hay que admitir que coadyuva en el acercamiento a estas temáticas una mirada transatlántica, que cobrará cuerpo poco después de la publicación de $M i k a$, a través de la posibilidad de inserción en otras manifestaciones de interés por la Guerra Civil y el franquismo desde el lejano Sur, por parte de una de las "hijas patrias": el surgimiento de la Plataforma Argentina de Apoyo a la Querella contra los Crímenes del Franquismo. ${ }^{9}$ Elsa Osorio sostiene un vínculo con la mencionada Plataforma, y participa con frecuencia en el apoyo y la difusión de sus actividades. En este tipo de prácticas, se recicla y revitaliza un interés por España que puede retrotraernos a los días de la Guerra Civil, ${ }^{10}$ a una continuidad de ayuda material y a un grado de compromiso que incluyó distintas disciplinas y manifestaciones. ${ }^{11}$ Entre esas expresiones, también la elección estética y a la vez ética que implicó inmiscuirse en la materia a través de la letra escrita subsumió a autores argentinos desde el comienzo:

Los intelectuales argentinos, tomando partido con furia vociferante, respondieron a ese dolor de España con una amplísima, casi inabarcable producción de ensayos, 
poemas, narraciones y obras dramáticas. Muchos viajaron a España y enviaron a casa textos testimoniales cargados de asombro y emoción. Para casi todos, más allá del bando que apoyaban, España era otra vez la madre patria, una madre que se desangraba en el prolongado y brutal parto de su futuro. (Binns 23)

Niall Binns recopila en su volumen sobre Argentina y la Guerra Civil española textos de una cantidad de autores argentinos que se abocaron a dar cuenta, mediante escritos en distintos soportes y a través de variados géneros, de su mirada respecto del conflicto, de manera más o menos breve, con continuidad o no, pero en todos los casos con un grado de interés que trasciende modalidades literarias y posicionamientos políticos. Juan L. Ortiz, Eduardo Mallea, Raúl González Tuñón, Cayetano Córdova Iturburu, María Rosa Oliver, Luis Alberto Quesada, Fanny Edelman y Mika Etchebéhère son algunos de ellos.

El salto diacrónico de un renovado acercamiento literario rastreable en un puñado de obras de los últimos diez años que vuelven a fijarse en la Guerra Civil española desde Argentina tiene en la novela de Osorio un caso insoslayable. ${ }^{12}$ La focalización narrativa en una guerra que en parte es ajena pero que involucra una empatía y una serie de acercamientos previos y simultáneos - tiene su correlato también a nivel de la trama, ya que a la propia Mika hay quienes le achacan el haberse inmiscuido en una guerra de otro país. El señalamiento casi acusatorio de extranjería es un encasillamiento que no amaga siquiera a intentar comprender el carácter internacionalista de aquello por lo que se luchaba y las resonancias globales que la Guerra Civil española tuvo - la participación de la aviación alemana en los bombardeos, las relaciones de Hitler y Mussolini con Franco, la presencia de las Brigadas Internacionales, etc.

Es llamativo que el contrapunto entre posiciones encontradas acerca de la pertenencia o las posibilidades de interpretación ante una u otra guerra, se establezca en la novela en un vaivén entre apreciaciones sobre la Guerra Civil española y la Guerra de las Malvinas. Este cruce atlántico de episodios traumáticos tan distantes - cronológica y geográficamente trastoca cualquier atribución de pertenencia y de identificación que se ampare solo en cuestiones territoriales y de bandera:

El recuerdo de esa reunión con unos argentinos que viven en Francia, tan exaltados como están por la Guerra de las Malvinas, le pone los pelos de punta. Cuánto se enojó Mika esa noche. De ahí la necesidad de evocar la guerra de España con sus camaradas.

-Vos que combatiste en la guerra de España, deberías enrolarte - le dijo ese hombre, un exiliado por la dictadura [argentina]. 
Mika no llegó a formar una frase, la sorpresa le deformó el gesto, ¿qué decía?, ¿la estaba cargando? Él la miró, le sonrió, y condescendiendo a sus años: Si no para la batalla, para asesorar, para darles fuerza a los soldados.

-Sí - apoyó el otro -. Y qué bueno sería para vos, por fin una guerra tuya, de tu país, no una guerra ajena. (44-45)

La omnisciencia de la voz narradora se inmiscuye en la reacción del personaje, que pelea internamente para no discutir. Por otra parte, a diferencia de otras intervenciones dialógicas, la identificación de estos compatriotas exiliados no se produce, como si la voz narradora se mostrara empática con el esfuerzo de tolerancia de Mika frente a dos entusiastas de una guerra absurda como tantas, pero sobre todo desigual e inoportuna. ${ }^{13}$ Los dos interlocutores de Mika acaban despertando una indignación de la que la voz narradora se hace eco al incorporar un diálogo encendido, de marcados matices agonísticos, ya sin lugar para que se haga presente la reflexión, la lucha interna por dominar un impulso:

- ¿Y es tuya, es de ustedes, la guerra de las Malvinas? ¿No son esos fantoches que la declaran los mismos que asesinaron a sus compañeros, los que los expulsaron de Argentina? ¿O ya no recuerdan por qué están en Francia? (45)

A continuación, toda posibilidad de diálogo se diluye. Una vez más la escritura de Osorio se hace cargo y acompaña sintácticamente la escena recreada, pues la discusión se incorpora, desordenada, a un estilo indirecto libre que ilustra un disenso in crescendo:

Aún la araña la imagen de esos hombres y mujeres gesticulando, sus voces chillonas, su soberbia: Los vamos a hacer de goma con los Exocet. Y Mika, casi gritando: que ni su oficio conocen los generales del crimen, ignorantes, asesinos y brutos, deberían ser fusilados en la plaza pública, no tienen vergüenza esos señores que ahora se arrodillarán a los pies de Estados Unidos. ¿Pensaron cuántos muchachos muertos, amputados o ciegos dejará esta guerra? (45-46)

La aglutinación de sentimientos y el desorden violento de las palabras se abisma en la imposibilidad de escucha atenta que prospere en un intercambio de opiniones. A esa confusión se suma la particularidad de que los dos sujetos innominados, con quien se mantiene la discusión sobre esta nueva guerra, se disuelven en la imagen de una multitud de hombres y mujeres que gesticulan con soberbia. Se amplía, entonces, el campo del señalamiento crítico. En este punto, el personaje de Guillermo Núñez interviene y restablece cierta calma necesaria para un balance y una fase 
posterior de hallazgo de voces coincidentes acerca de la gravedad del conflicto argentino: $:^{14}$

¿Era una amenaza? Mika sentía que la sangre le subía a la cara, vergüenza le daban, indignación, furia. Por suerte su amigo Guillermo Núñez, que piensa lo mismo que ella, estaba ahí, la tomó del brazo, y la arrancó de ese infierno al que se estaba dejando arrastrar. (46)

Pero es Julio Cortázar, incorporado también como personaje, con quien llega otro grado de pacificación y a la vez una mirada que funciona como cita de autoridad y ratifica las razones esgrimidas por Mika. Cortázar y su palabra escrita ofrecen una base sólida para encauzar el estallido oral e indignado de "la capitana":

En Le Monde lee una declaración en la que su amigo Julio Cortázar y otros intelectuales denuncian el engaño y la manipulación de los dictadores. Lo llama por teléfono:

-Bien hecho, Julio, me alivió leer lo que dijiste sobre la Guerra de las Malvinas. Tenemos que hablar. Escuché unos comentarios tan pero tan insensatos de unos exiliados argentinos en París... (46)

Desde modalidades diferentes de intervención, el consenso con Cortázar a propósito de la Guerra de Malvinas ofrece una nueva ilación entre los dos conflictos bélicos. En el título de este apartado, en el que venimos desarrollando la problemática de la distinción entre una guerra ajena y una guerra propia, se jugaba con el título del libro de cuentos de Cortázar Todos los fuegos, el fuego. De algún modo, sin extrapolaciones puntuales que impedirían una comparación entre ambas guerras, por innegables elementos de inconmensurabilidad, este pasaje de la novela que incorpora debates que fluyeron por distintos medios tiende un puente transatlántico que redimensiona además otras luchas en las que siempre se sacrifica a los sectores más vulnerables. En este punto, si bien "todas las guerras" tienen sus características, y no todas las luchas pueden entrar en el mismo ámbito de denominaciones, se vuelve a traer a cuento la represión de la ya mencionada Semana Trágica en Argentina, como piedra de toque de la participación activa de Hipólito Etchebéhère en un camino que luego compartirían:

Julio tiene razón, le está dando más importancia de la que merece. Qué indignación le hubiera causado a Hippo escuchar que la guerra de España fue una 
guerra ajena. La revolución está donde hay una mecha preparada para encender. Él lo entendió desde muy joven, tenía diecinueve años.

Como escribiste en La bataille socialiste en 1965: "En esa 'semana trágica' de enero de 1919 que quedó en los anales de la represión argentina como un hito sangriento, Hipólito Etchebéhère entró en la revolución como otros entran en una orden religiosa: para siempre, hasta el último latido de su corazón, con un odio lúcido y razonado, alerta siempre, afilado cada día, tenso como la cuerda de un arco listo para disparar contra ese orden social absurdo, rapaz y asesino". (47-48; cursiva y espacio entre uno y otro párrafo en el original)

La operación literaria de selección y combinación es notoria. Por un lado, en letra redonda, la reflexión del personaje de Mika utilizando para sí la tercera persona, distanciándose, contribuye a aplacar el fuego del sentimiento de indignación. Además de la cita que sostiene su opinión sobre la guerra que sí sería supuestamente "propia", refrendada no solo por la opinión oral y amistosa de Cortázar sino también por el texto de $L e$ Monde, se apela a la imaginación para incorporar otra voz que habría sido autorizada y se fantasea con la mirada que habría tenido Hipólito ante la inexactitud de que la Guerra Civil española pueda pensarse como ajena. Asimismo, la vuelta a la letra cursiva con que la voz narradora se dirige a la protagonista en un ejercicio de memoria, con apariencia de intimidad pero a su vez con una impronta insistente, por momentos de tono pedagógico, se refuerza la idea de delinear un sistema de distintas luchas a lo largo de épocas y latitudes divergentes.

REFLEXIONES FINALES Y CONTINUIDAdES EN PRIMERA(S)
PERSONA(S)

En un empleo de la primera persona de singular que encarna tanto la voz narradora como la instancia de autoría y, a su vez, la permanente cesión de la voz al personaje biografiado y novelado, el texto de hechura argentina que se analizó - atravesado por conflictos puestos en proyección con la materia histórica principal que se propone contar - ficcionaliza una participación argentina muy concentrada y particularmente fértil para la literatura y para los estudios de la memoria. A lo largo del análisis se han vislumbrado varias modalidades de descentramiento que hacen a una determinada configuración de la memoria del pasado traumático. Por un lado, a diferencia de otros rescates literarios de heroicidades vinculadas al conflicto bélico peninsular, la protagonista es una mujer que llega a ocupar un alto rango. Por otro lado, el ejercicio de memoria literaturizada no lo lleva a cabo un autor o una autora española que repongan narrativamente un silenciamiento en la historia de su propio país, sino que lo realiza una 
escritora que aborda su objeto de estudio con las dificultades de la distancia geográfica y la no pertenencia de origen a un tema complejo, con consecuencias más evidentes para quienes lo sufrieron o para sus descendientes. Un tercer plano de descentramiento está dado por el desplazamiento de foco que conlleva la necesidad de acceder a una documentación mediada, por la marca generacional y el agregado de la falta de cotejo directo con quien habría sido la fuente por excelencia, la propia protagonista. Es de destacar que el proceso de construcción de un procedimiento discursivo que acerque lo que está irremediablemente lejos depende de un trabajo en torno a vivencias individuales. Esto se produce en el marco del giro subjetivo reconocido especialmente en la última década. Hay un notorio retorno del sujeto. No se anula en ningún modo la importancia de las reflexiones en derredor de la memoria colectiva, que desde Maurice Halbwachs ha implicado una conciencia de la condición de la memoria como parte de una red de relaciones sociales. Pero sí ocurre que la literatura vuelve a hacerse cargo de conjurar silenciamientos y riesgos de que, a casi ochenta años del conflicto, se vayan disolviendo las posibilidades de acceso a porciones relevantes de historias individuales que quedaron opacadas u ocultas. A su vez, tiene peso la importancia que adquiere el espacio biográfico en la subjetividad contemporánea, notoria en

la visibilidad que "lo personal" ha adquirido como lugar no simplemente de intimidad sino de manifestación pública. La "propia" experiencia es un valor privilegiado y es allí, en la expansión de lo biográfico donde puede leerse un proceso de reconfiguración de la subjetividad contemporánea que trae nuevas formas de relatos en los que narración y memoria adquieren contornos renovados. (Vallina 12-13)

De aquellas memorias tituladas Ma guerre d'Espagne à moi de 1975 hasta la última reedición hasta el momento, Mi guerra de España, que en 2014 realizó la editorial Eudeba, ha pasado mucho tiempo. El Cortázar literaturizado en la novela de Elsa Osorio se hace presente de puño y letra en la edición de Eudeba de las memorias, ya que el libro se inicia con la reproducción facsimilar de la carta dirigida a Mika en la que Julio Cortázar acusa recibo del manuscrito. Cabe recordar que herederos de Mika Etchebéhère (con ese apellido únicamente es que aparece ella en los paratextos que atañen a derechos y a la descripción física del libro de Eudeba), Fito Pochat y Javier Olivera (sobrinos nietos de Hipólito) dirigieron, con posterioridad a la novela de Osorio, el documental Mika, mi 
guerra de España, por lo cual el personaje es cada vez menos dejado de lado por diferentes soportes de narración.

La primera persona, tan acentuada en el título de las memorias, da cuenta nada menos que de la vivencia en carne propia de una guerra supuestamente ajena por convicciones compartidas de modo genuino. Esa primera persona que se diluye bastante más en las decisiones estilísticas del texto que hemos analizado es susceptible, por cierto, de nuevos abordajes en la medida en que se la ponga en relación con otras textualidades, documentales y de creación estética. En materia de detenimiento en un pasado traumático que atravesó décadas, latitudes y géneros, la literatura argentina - por resonancia de consecuencias traumáticas propias y por corolarios de emigración y exilio vinculados a España - sigue potenciando una indagación en la que habrá modalidades disímiles, géneros e intereses encontrados, pero en la que sin duda la memoria de la Guerra Civil no es en modo alguno un elemento foráneo.

Instituto de Investigaciones en Humanidades y Ciencias Sociales Universidad Nacional de La Plata / CONICET

\section{NOTAS}

1 Este artículo se inscribe en el Proyecto de Incentivos a la Investigación "Diálogos transatlánticos. España y Argentina: campo editorial, literatura, cultura, memoria (1940-2013)" de la UNLP (código H742), dirigido por Raquel Macciuci y codirigido por Fabio Espósito, y en la investigación financiada por el Plan Nacional I+D del Programa Estatal de Fomento de la Investigación Científica y Técnica de Excelencia. Ministerio de Economía y Competitividad de España (Ref. CSO2O13-41594-P). Forma parte, a su vez, del plan de beca postdoctoral de CONICET con lugar de trabajo en el Instituto de Investigaciones en Humanidades y Ciencias Sociales (UNLP-CONICET).

2 El hecho de la historia argentina conocido como "Semana Trágica", ocurrido en enero de 1919 en la ciudad de Buenos Aires, se origina en una huelga de obreros de los Talleres Metalúrgicos Vasena que derivó, en principio, en un enfrentamiento con las fuerzas policiales. La organización sindical FORA (Federación Obrera Regional Argentina) reaccionó con una huelga general que paralizó la ciudad una semana. Más allá de la represión policial contra los trabajadores, ocurrió que en el seno de la alta burguesía, que vivía el contexto de la Revolución rusa como una amenaza presuntamente responsable de la huelga, se fue incrementando un sentimiento contra todo lo percibido como foráneo. Como consecuencia, se desató una suerte de fervor nacionalista que 
derivó en un acentuado odio condensado en la "Liga Patriótica", una suma de tropas informales de jóvenes provenientes de familias acomodadas que perpetraron ataques de extrema violencia. Las acciones policiales, militares y parapoliciales contra los trabajadores fueron acompañadas por otras de corte marcadamente antisemita. Aún hoy se discute la cifra de muertos, que se estima en centenares, y han quedado bastante soslayados algunos nombres de la historia política argentina vinculados a la Semana Trágica. Lo que resulta más difícil de discutir es que constituye un episodio de resistencia y lucha por derechos laborales que finalmente fueron otorgados y que otros sectores obreros ya habían conseguido: el reclamo de los metalúrgicos consistía, en lo esencial, en la jornada laboral de ocho horas y en la existencia de un día de descanso (Osorio, Mika 49-52; Bayer).

3 Es llamativo que en este pasaje localizable en España se le asigne a Ruvin Andrelevicius, en una instancia en la que ya cayeron los diferentes velos onomásticos, el nombre falso con el que Mika lo conoció en Alemania, espejando la imposibilidad de distanciamiento respecto de esa primera experiencia traumática.

4 Se ha publicado con posterioridad (a comienzos del corriente año, 2015) otra novela titulada La capitana, de la escritora argentina Graciela Ramos, que claramente no se centra en la materia abordada por Elsa Osorio. Se menciona aquí este dato simplemente con la intención de evitar toda posibilidad de confusión. En cualquier caso, y más allá del acierto que supone un título coherente con el tratamiento cercano que se establece con el personaje de Micaela Feldman, se presume que en términos editoriales, especialmente para Osorio si la publicación argentina no hubiera llevado el título Mika, no habría sido demasiado conveniente la coincidencia.

5 Este procedimiento, la inclusión de un apartado bastante puntilloso de agradecimientos, es habitual en las novelas de la memoria de la Guerra Civil española. Menciono como ejemplos significativos el agradecimiento en tres etapas que se presenta al final de la novela La voz dormida, de Dulce Chacón, y la nota de la autora titulada "Al otro lado del hielo" en la novela El corazón helado, de Almudena Grandes, nota con la que luego de más de mil doscientas páginas de narración se aclara el estatuto ficticio del relato, pero a la vez se incorporan detalles de fuentes, episodios y lugares que anclan la narración en distintos pasajes de la historia, seguido todo esto de una desarrollada lista de agradecimientos, con diferentes destinatarios de esos agradecimientos, unidos a la explicación que los motiva.

6 En este punto viene a cuento señalar que es un rasgo de la novela histórica contemporánea colocar paratextos que son ficticios.

7 De hecho, el mismo Prévan figura como facilitador de documentos para la re- 
edición de las memorias de Mika en Eudeba, en 2014, en cuyo copyright se incluye a los herederos de la viuda de Hipólito Etchebéhère.

8 Por nombrar sólo algunas novelas, que podrían crecer hasta componer una lista de cientos de títulos: Las esquinas del aire. En busca de Ana María Martínez Sagi (Juan Manuel de Prada, 200o), Soldados de Salamina (Javier Cercas, 2001), La voz dormida (Dulce Chacón, 2002), El hijo del acordeonista (Bernardo Atxaga, 2003), Enterrar a los muertos (Ignacio Martínez de Pisón, 2005), Mala gente que camina (Benjamín Prado, 2006), Los libros arden mal (Manuel Rivas, 2006), Hombre sin nombre (Suso de Toro, 2006), El corazón helado (Almudena Grandes, 2007).

9 Para explicar su constitución, citamos la respuesta que brindó Adriana Fernández, una de sus integrantes, a la revista Olivar. Esta otra argentina, que hace pocos años recuperó los restos de su abuelo y pudo conocer el verdadero motivo de su muerte, un asesinato vinculado a una represalia en el marco del conflicto español, explica: "La Plataforma se lanzó el 3 de septiembre de 2013. Está conformada por representantes de organismos de DD.HH., organizaciones políticas, estudiantiles, gremiales, culturales, profesionales y ciudadanos en general. Surgió ante la necesidad de contar con una red de apoyo como las que se fueron formando en distintas regiones del estado español ... para difundir la existencia de este juicio [por los crímenes franquistas], los diferentes testimonios que se van sumando a la querella (robo de bebés, trabajo esclavo, torturas, preventorios, etc.) y dar a conocer el genocidio que se cometió y que se ha tratado de tapar por más de 70 años" (Sánchez 278-279).

10 Son conocidas las historias del apasionamiento con que se vivió el conflicto en Argentina. Suele aludirse a reyertas desencadenadas en establecimientos de café de la Avenida de Mayo, en la ciudad de Buenos Aires. Se cuenta que los partidarios de uno y otro bando español llevaron adelante una discusión ideológica que sobrepasó en ocasiones el intercambio verbal, llegándose a arrojar sillas de vereda a vereda.

11 "Bien sabemos que durante el conflicto bélico, numerosos intelectuales españoles postergaron su profesión para servir a la República, tanto en tareas civiles como militares. No todos lograron convalidar sus títulos universitarios en los países en que pasaron a residir como consecuencia de la guerra. Manuel Blasco Garzón, por ejemplo, que había sido cónsul de España en Buenos Aires hasta la llegada de las autoridades franquistas, tuvo que ganarse la vida vendiendo seguros, dictando clases particulares y pronunciando conferencias o escribiendo artículos periodísticos. Sin embargo, gran parte de los refugiados lograron retomar sus profesiones en el exilio. Para con ellos, algunas de las universidades nacionales desempeñaron un papel muy importante, ya que les brindaron el espacio académico para que pudieran continuar su tarea. Entre estas, las de Buenos Aires, Cuyo, el Litoral, Tucumán y La Plata incorporaron a 
sus claustros profesores españoles especialistas en diversas disciplinas" (Pochat).

12 Además de la novela que se analiza aquí, otras obras recientes de autores argentinos que toman la Guerra Civil española son Yo nunca te prometí la eternidad (Tununa Mercado, 2004), Tío Borís. Un héroe olvidado de la guerra civil española (Graciela Mochkofsky, 2006), Teruel y la continuidad del sueño (Manuel Santos Iñurrieta, 2009) y La abuela civil española (Andrea Stefanoni, 2014), entre otras.

13 Recordemos que la Guerra de Malvinas fue declarada a Inglaterra en 1982 por la última dictadura militar de Argentina (1976-1983) con el objetivo de recuperar el territorio de las islas (las Malvinas entre otras) que se encuentran en la plataforma continental argentina. Si bien es innegable que hay motivos históricos y geográficos como para que a futuro se vuelva a plantear la soberanía sobre las islas, es un hecho comprobado que no había en 1982 ningún atisbo de una política pertinente para replantear la añeja apropiación ni la posesión del terreno. Se trató más bien de un último recurso dictatorial ante el advenimiento de un anunciado eclipse del régimen de facto.

14 Fuente de Osorio a quien se le dedica un apartado muy detenido en los agradecimientos finales, y de quien se dice: "Mika estaba tan viva en él que sucumbí a la tentación de hacerlo personaje de mi novela. Ella contándole sus aventuras a su joven amigo" (296).

\section{OBRAS CITADAS}

AtXaga, Bernard o. El hijo del acordeonista. Madrid: Alfaguara, 2004.

BAye R, o SVAld o. "La Semana Trágica”. Página 1216 enero 2006. S. pag. Web.

—. La Patagonia rebelde. México, D.F.: Nueva Imagen, 1980.

B IN NS, N I ALl. Argentina y la guerra civil española. La voz de los intelectuales.

Madrid: Calambur, 2012.

CERCAS, JAVier. Soldados de Salamina. 2ª edición. Buenos Aires: Tusquets, 2004.

CHACón, Dulce. La voz dormida. Buenos Aires: Alfaguara, 2008.

Cifuentes aldunate, Claudio. "La a-historicidad de la novela del fragmento: de Rayuela a Nocilla Dream". La memoria novelada. Hibridación de géneros y metaficción en la novela española sobre la guerra civil y el franquismo (20002010). Eds. Hans Lauge Hansen y Juan Carlos Cruz Suárez. Bern: Peter Lang, 2012. 233-245.

CORREDERA GONZÁLEZ, MARÍA. La guerra civil española en la novela actual. Silencio y diálogo entre generaciones. Madrid/Franfurt: Vervuert/Iberoamericana, 2010.

Cortázar, julio. Todos los fuegos, el fuego. Buenos Aires: Sudamericana, 1966. 
et Che в É È Re, mika. Mi guerra de España. Buenos Aires: Eudeba, 2014. GÓMEZ LÓPEZ-QUiÑones, ANTONio. La guerra persistente. Memoria, violencia y utopía: representaciones contemporáneas de la Guerra Civil española. Madrid/Frankfurt: Iberoamericana/Vervuert, 2006.

GRANDES, ALmudena. El corazón helado. Buenos Aires: Tusquets, 2010.

HA L B W A C HS. MA U I C E. La memoria colectiva. Trad. Inés Sancho-Arroyo. Zaragoza:

Prensas Universitarias de Zaragoza, 2004.

MACCIUCI, RAQUEL. "La memoria traumática en la novela del siglo XXI. Esbozo de

un itinerario". Entre la memoria propia y la ajena. Tendencias y debates en la

narrativa española actual. Dir. Raquel Macciuci y María Teresa Pochat. La

Plata: Ediciones del lado de acá, 2010. 17-49.

MARTÍNEZ DE PISÓN, I gNACio. Enterrar a los muertos. Barcelona: Seix Barral, 2005.

MERCA Do, T Un UnA. Yo nunca te prometí la eternidad. Buenos Aires: Booket, 2013.

Mika. Mi guerra de España. Dir. Pochat, Fito y Javier Olivera. Motoneta Cine, 2013.

м о С н ко г ку, G R A Ci L LA. Tío Borís. Un héroe olvidado de la guerra civil española.

Buenos Aires: Sudamericana, 2006.

os o R I O, E LSA. Mika. Buenos Aires: Seix Barral, 2012.

-. A veinte años, Luz. Buenos Aires: Planeta, 2006.

PoCHAT, MARía TERESA. "Memoria de la guerra de España en la voz de

intelectuales argentinos". Actas del Tercer Congreso Internacional de Literatura

y Cultura Españolas Contemporáneas, Octubre 8-10, 2014 Universidad Nacional de La Plata. S. pag. Web.

PRA DA, JuAn man u L DE. Las esquinas del aire. En busca de Ana María Martínez

Sagi. Barcelona: Planeta, 2000.

PRAD O, Benjamín. Mala gente que camina. Madrid: Alfaguara, 2009.

RAMOS, GRACIELA. La capitana. Buenos Aires: Suma de letras, 2015.

RIVAS, MANUEL. Os libros arden mal. Vigo: Xerais, 2006.

SÁNCHEZ, MARIELA. “'Historias olvidadas en las cunetas'. Entrevista con Adriana

Fernández, integrante de la Plataforma Argentina de Apoyo a la Querella

contra los Crímenes del Franquismo". Olivar. Revista de Literatura y Cultura

Españolas 14.20 (2013): 271-285.

Sant os IÑuR Rieta, Manuel. Teruel y la continuidad del sueño. Buenos Aires:

Centro Cultural de la Cooperación Floreal Gorini, 2009.

St E FAn ON I, An DREA. La abuela civil española. Buenos Aires: Seix Barral, 2014.

TORO, SUSO DE. Home sen nome. Vigo: Xerais, 2006.

TARCUS, h o RA C I o. "Insurrexit. Revista universitaria (1920-1921)". LOTE 8 (1997): S. pag. Web.

TSCHILSCHKE, CHRISTIAN VON Y DAGMAR SCHMELZER. "Docuficción: un fenómeno limítrofe se aproxima al centro". Docuficción. Enlaces entre ficción y no-ficción en la cultura española actual. Eds. Christian von Tschilschke y Dagmar

Schmelzer. Madrid/Frankfurt: Iberoamericana/Vervuert, 2010. 11-32. 
VAllina, CeCilia. "Un recorrido crítico por el relato testimonial". Crítica del testimonio. Ensayos sobre las relaciones entre memoria y relato. Ed. Cecilia Vallina. Rosario: Beatriz Viterbo Editora, 2009. 10-22. 